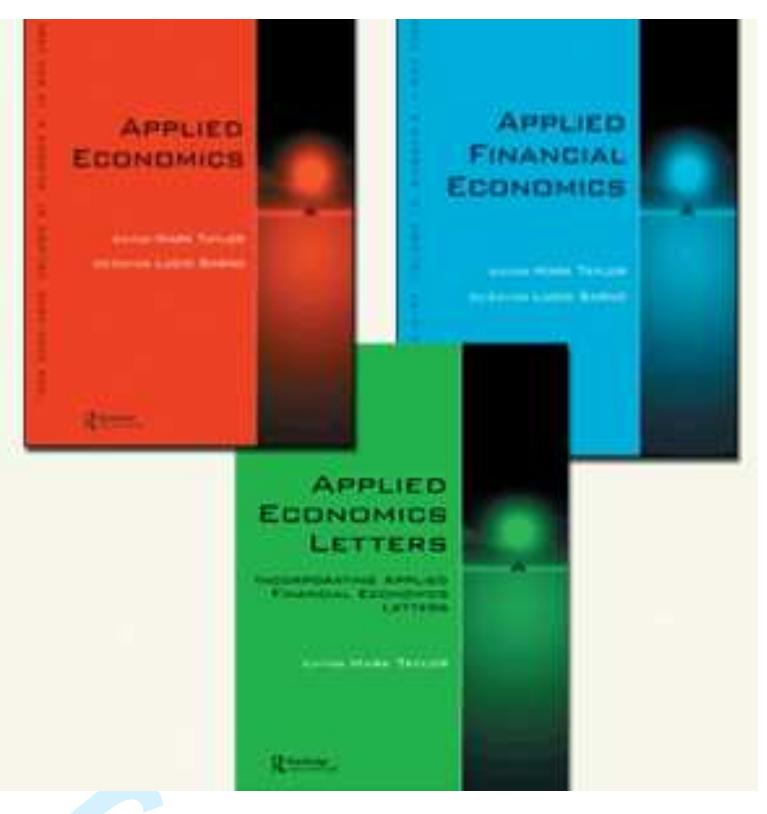

\title{
Characterizing Spanish Labour Pathways of young people with vocational lower-secondary education
}

\begin{tabular}{|r|l|}
\hline Journal: & Applied Economics \\
\hline Manuscript ID: & APE-2010-0174.R1 \\
\hline Journal Selection: & Applied Economics \\
\hline Author: & 01-Dec-2010 \\
\hline Complete List of Authors: & $\begin{array}{l}\text { Corrales Herrero, Helena; Universidad de Valladolid, Economía } \\
\text { Aplicada } \\
\text { Rodríguez Prado, Beatriz; Universidad de Valladolid, Economía } \\
\text { Aplicada }\end{array}$ \\
\hline JEL Code: & $\begin{array}{l}\text { J24 - Human Capital|Skills|Occupational Choice|Labor Productivity } \\
<\text { J2 - Time Allocation, Work Behavior, and Employment } \\
\text { Determination/Creation < J - Labor and Demographic Economics, } \\
\text { J64 - Unemployment: Models, Duration, Incidence, and Job Search } \\
<\text { J6 - Mobility, Unemployment, and Vacancies < J - Labor and } \\
\text { Demographic Economics, I21 - Analysis of Education < I2 - } \\
\text { Education < I - Health, Education, and Welfare }\end{array}$ \\
\hline Keywords: & \begin{tabular}{l} 
school-to-work transition, sequence analysis, vocational training \\
\hline
\end{tabular} \\
\hline
\end{tabular}




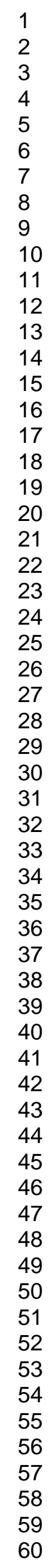

\section{SCHOLARONE ${ }^{m}$ \\ Manuscripts}

7 


\title{
Characterizing Spanish Labour Pathways of Young People with Vocational Lower-Secondary Education
}

\author{
H. Corrales-Herrero ${ }^{\mathrm{a}, *}$ and B. Rodríguez-Prado ${ }^{\mathrm{a}}$ \\ ${ }^{a}$ Departamento de Economía Aplicada, University of Valladolid \\ Avenida del Valle de Esgueva, 647011 Valladolid, España \\ *Corresponding author. E-mail: helena@eaee.uva.es
}

School-to-work transition is no longer considered to take place at one point but it is seen as a sequential process with multiple stages that extend over a relatively long period in which individuals gradually settle down into the labour market. This paper constructs and examines the labour pathways followed by Spanish young people who have completed vocational lower-secondary education. To do so, we use the Survey on Educational-Training Transition and Labour Integration, a retrospective longitudinal dataset that contains monthly calendar information about the labour states in the four years after completing vocational education. A wide range of states is covered: part-time employment, full-time employment, unemployment and several situations of inactivity. To examine young labour pathways we use sequence analysis, an exploratory technique which allows us to obtain a measure of dissimilarity between sequences. Later, a cluster analysis is applied that allow us to identify seven patterns of transition into the labour market. Nevertheless, most trajectories may be classified as linear, with a successful integration into the labour market. A multinomial logit model confirms that demographic and educational variables are relevant to explain the pathways followed by young people. 


\section{Introduction}

School-to-work transition is no longer considered to take place at one point but it is seen as a sequential process with multiple stages that extend over a relatively long period in which individuals gradually settle down into the labour market (OECD, 2000; Ryan, 2001). Besides, routes between school and work are not always linear but involve breaks, divergences and reversals. According to this, school-to-work transition analysis has to take into account this transitory period as a whole, and it is not sufficient to focus on single events such as the moment to achieve a first job. On the contrary, single events have to be understood in their continuity and should not be isolated from each other. Approaching the entry process in this way, both the speed of finding jobs and the stability of jobs bring into focus. The speed has implications for the amount and duration of unemployment spells, while job stability approximates the quality of the match. Consequently, a more appropriate data to analyze the entry to labour market must contain the sequence of the labour states each individual is passing through to reach the labour market integration or, in other words, the serial succession of states describing the structure and composition of the labour pathway.

There is a large tradition of research arguing that the pace and the smoothness of transition to work are primarily determined by the educational background (Scherer, 2005; Corrales and Rodríguez, 2004). In this sense, it is interesting to know the role that vocational education plays in the labour market outcomes as well as in the way the transition between the two systems performs. Labour market entrants already qualified for an occupation do not have to be trained (at least at the same extent as school leavers with only general education) and therefore, they are expected to find a job that matches more successfully. 
However, the occupational specificity of vocational education makes difficult to adjust skill demands to the rapid changes into the labour market. Then, different outcomes, in the case of individuals with vocational education say something about the real qualifications and skills of graduates as well as the degree of mismatch between the labour demand and supply in some areas of vocational specialization.

Vocational training in Spain has been subjected to a substantial reform in the last years and new tackles into employment has been established. ${ }^{1}$ The current regulated vocational training is integrated into the education system and it is divided into two levels: lower and upper vocational training (Homs, 2009). Lower vocational training is inside the upper secondary education while upper vocational training is an alternative to university.

Both of them have a modular structure of variable duration which goes from 1300 to 2000 hours, organised in one or two years. There are two types of modules: theoretical-practical modules, aimed at developing a series of vocational capabilities previously defined in relation to jobs, and a practical training module, known as the Training in the Workplace module, which is done in a real workplace (rather than in the educational centre) generally through internships in a company. Students are supervised by a school tutor and a workplace tutor who develop a work plan for them. The internship represents 25 percent of the teaching time of a cycle and it is also evaluated. This work-linked training module does not reach the level of alternation of Germany's dual system, nor the programmes of training in alternation with employment of the French system, but it has contributed to overcoming the traditional isolation of training centres from

\footnotetext{
${ }^{1}$ Nowadays, Spanish Vocational Training is ruled by the Act on the General Organization of the Education System (LOGSE) passed in 1990.
} 
businesses and it recognizes of the importance of on-the-job training as an aspect of vocational training.

It is also important to point out that the vocational training cycles are organized by occupational families, which are large groupings by occupation or vocation, some of a more sector character and others more transversal but which cover the majority of vocational content in the labour market. The National Institute of Qualifications updates periodically the number and definition of these occupational families. Nowadays, there are 26 occupational families, which cover the primary sector, with farming activities and maritime and fishing activities; the secondary sector, with for example, chemistry, mechanical production, electricity and electronics, graphic arts and the tertiary sector, such as hotel industry and tourism, socio-cultural and community services, health, etc.

With respect to lower vocational training, it constitutes the path for vocational specialization for those students who successfully complete basic education ${ }^{2}$ and want to join to the labour market. ${ }^{3}$ It could be said that vocational training is a basic means of providing directly access to employment. So, if the system fails to match workers' occupational profiles to economic and social requirements, serious consequences in terms of exclusion may appear. ${ }^{4}$

On the other hand, Spanish youth labour market has faced some changes derived from growing flexibility, expansion of educational system and the skill biased technological progress (Dolado et al., 2000) that may also affect the

\footnotetext{
${ }^{2}$ Access to the lower-level cycles can be attained once the certificate of basic education has been obtained. This requirement, which insures a minimum level of knowledge and abilities, has contributed to increase the quality of these training cycles.

${ }^{3}$ In the academic year 2000/2001 there were 304580 people enrolled in lower vocational training system, of which 130715 were women. This represents $28 \%$ of total students enrolled in upper secondary education and $24 \%$ of women. In 2008/2009 the rates have increased and $32 \%$ of all students enrolled in upper secondary education opt for vocational studies (28\% of women).

${ }^{4}$ Also, low retention rates and drop-outs could increase the exclusion problem.
} 
transition to work for vocational students. These authors have provided evidence of a crowding-out effect, what means that the lower educated workers are replaced by higher educated ones in their traditional entry jobs.

The aim of this article is to identify typologies of transitions from school to work in the early years after leaving vocational lower-secondary education in Spain in the light of the last changes in vocational training. A detailed examination of these patterns allows identifying the pathways which conduct more frequently to a job as well as to detect which fail to integrate students into the labour market. This information would be of great usefulness for designing political measures aimed to facilitate the integration of young people into the labour market and to design efficiently vocational programmes.

The analysis consists of two parts. First, the youth labour trajectories are compared using the sequence analysis. This technique was first introduced to Social Sciences in the form of Optimal Matching Analysis (OMA). The idea behind OMA is that the similarity between sequences can be expressed as the cost of turning one sequence into another by applying a set of operations (substitution, insertion and deletion). We apply a recent extension of sequence analysis, the modified Hamming dissimilarity measure (Lesnard, 2006) that enables us to account for time dependent substitution costs. This initial step ends up by applying a cluster analysis taking as input the distance matrix obtained previously, and grouping trajectories that are very similar. As a second step, a multinomial logit model is estimated to evaluate the role of some demographic and educational variables in determining individual pathways.

The paper is organised as follows. The next section provides a short review of literature on this topic. Section 3 gives a description of data used in the empirical 
analysis. The fourth section explains details of the techniques applied (sequence analysis and cluster analysis) and some specifications in the application to our data. Next, the results of a multinomial logit analysis are presented and discussed. A robustness analysis is included in section 6 and the final section incorporates the main conclusions.

\section{Review of literature}

The study of the first attempts to enter into the labour market has raised great interest among labour economists and a large literature can be found on this issue (OECD, 2000; Ryan, 2001; Raffe, 2003; Davia, 2004; Casquero, 2007 for the Spanish case). One of the most relevant results is that the school-to-work transition process has become longer and more complex due to the growing importance of intermediate states such as temporary jobs, rapid job-changing and instability. However, little research has examined each trajectory as a whole. In particular, we only find few papers handling this subject, mainly with a crossnational comparison approach (Scherer, 2001; McVicar and Anyadike-Danes, 2002; Brzinsky-Fay, 2007; Quintini and Manfredi, 2009). All of them apply a more recent and specific methodology to measure similarity between trajectories, the sequence analysis, and make homogeneous groups of trajectories using the cluster analysis. Sequence analysis allows them to handle the whole trajectory taking into account the information about the length and the ordering of states. In Scherer (2001), British and German youth trajectories are compared in order to discover distinct patterns of transition into the labour market and to know how they differ between different institutional contexts. McVicar and Anyadike-Danes (2002) focus on the transition process from education to labour market in Ireland. 
The main goal for these authors is to identify those background characteristics that have influence on the chances of experiencing a particular type of transition. Brzinsky-Fay (2007) compares the school-to-work transitions of young people for several European countries (included Spain) and classifies them in eight different typologies trying to find differences across countries supported by the country classification described in Gangl (2003). ${ }^{5}$ The dominant trajectory in Spain is the failure type, where unemployment is the primary state.

The most recent application of sequence analysis can be found in Quintini and Manfredi (2009) where school-to-work transition pathways in the United States and Europe are compared. Pathways in the United States are characterised by more dynanism than in Europe, although some similarities are found. Again, the dominant trajectory in Spain is the failure one. Also, Spain has the largest share of school-leavers in the "recovery" pathway, experienced prolonged unemployment but ultimately settle into work.

However, these papers are not strictly focused on the school-to-work transitions for people with vocational education. Studies focusing on the effect of vocational education have a more sociological perspective (Dolton et al., 1994; Arum and Shavit, 1995; Bonnal et al., 2002; Shavit and Muller, 2000; Ryan, 2003; Iannelli and Raffe, 2007). These studies do reach some general conclusion. Education systems in which students spent time learning and working in an enterprise, are generally noted for having low levels of youth unemployment and a smooth transition to work, because vocational training provides a close link

\footnotetext{
${ }^{5}$ Gangl (2003) distinguish between three patterns of school-to-work transitions depending on differences in educational systems. Spain is classified as a country with a low level of educational attainment and a weakly developed vocational training system.
} 
between education and work and also it is thought to provide a specific form of socialization to working life. ${ }^{6}$

Spanish research dealing with typologies of transition has basically followed a more qualitative approach (Cachón, 2000). According to this research, the predominant situation for young people in Spain is the "successive approximation", but the "precariousness" is actually playing a major role. However, the corresponding for young people with vocational training is the "precocious success", as they do not wait a long time to enter employment and their first jobs are quite stable.

\section{Data and basic concepts}

The data we analyzed is extracted from the Survey on Educational-Training Transition and Labour Integration (ETEFIL-2005). ${ }^{7}$ This survey has been the consequence of the concern about the high level of youth unemployment in Spain. Its main goal is to provide the essential elements to study jointly the pathways followed by young people both in the educational system and in the transition from education to work.

The sample comprises young people (younger than 26 years old in 2001) who finished non-university studies or abandoned the educational system without completing compulsory secondary education in the 2000/01 academic year. For the purpose of our analysis, we only deal with a subsample, the one formed by young people who finished vocational lower-secondary education. It consists of 7612 cases.

\footnotetext{
${ }^{6}$ To know more about several theories explaining the vocational effect on the transition from school to work see Iannelli and Raffe (2007).

${ }^{7}$ See INE (2007) for a more detailed description of data.
} 
The longitudinal structure of the survey, based on retrospective information on what young people have been doing in the early years after completing vocational education, allows us to know exactly the monthly serial succession of states which describes the structure and composition of the labour pathway. The pathway begins when individual leaves this level of education and ends when is interviewed in 2005 . Hence, the survey approximately reproduces the next four years after leaving education.

This information jointly with some other variables related to personal and education characteristics are used in the analysis. With respect to the labour states, the survey distinguishes up to 13 as a result of several combinations of the usual labour situations: employment, unemployment and inactivity. Such detailed information makes difficult the application of the proposed methodology. Therefore, it was necessary to cut the amount of labour states. Taking into account the overlap and interaction of educational and labour market situations in the early years after finishing vocational education, seems reasonable to distinguish various inactivity situations depending on the link to education (not studying, studying in the formal educational system or studying non-formal education). On the other hand, we have also distinguished between part and full-time jobs (working less or more than 20 hours a week). ${ }^{8}$ In short, the labour states contemplated appears in Table 1 and are the basic elements from which the trajectories are constructed.

\section{[Table 1 about here]}

Data on vocational training allow us to distinguish between gender and a broad number of areas of specialization (occupational families). These broad specialities include: agriculture, business, health care, trade, industry, marketing

\footnotetext{
${ }^{8}$ In any case, employment has always been the prevalent state. For instance, those individuals who are working part-time and studying at the same time are considered to be in the employment state.
} 
and services (see Table 2). It must be noted that there exists gender segregation by specialities. Some professional families are dominated by men, for example Electricity and electronics, whereas women are more prone to families related to Services sector as Health or Sociocultural and community services.

[Table 2 about here]

\section{Analysis of youth labour trajectories}

\section{A. Methodology}

The final objective is to classify the labour trajectories into groups, in such a way that trajectories belonging to the same group will be very similar and simultaneously, very different from trajectories in other groups. For this purpose, sequence analysis is used to compare the entry to labour market for young people with vocational lower-secondary education.

In the literature there are two approaches capable of systematically describing the sequence of events and their duration (Robette and Thibault, 2008). One of them is the Qualitative Harmonic Analysis (QHA), a factor analysis method developed by French statisticians in the 1980s which takes account of time (Espinasse, 1993; Robette and Thibault, 2008). The other is Optimal Matching Analysis (OMA), a set of algorithmic techniques imported from the Life sciences by American sociologists in the late 1980s which also emphasizes the order of events.

Before explaining the basic issues related to the OMA and discuss some methodological aspects of its application to our research problem we will describe briefly the main characteristics of QHA in order to understand the differences between these two methods. 
Harmonic analysis is a branch of mathematics widely applied in Physics and Biology. Its use in the Social Sciences is more recent, and dates back to the 1970s (Deville, 1974). The aim at that time was to use the notion of duration to explain social phenomena via data on individual trajectories.

QHA involves defining an observation period, dividing it into a finite number of intervals then measuring for each individual the proportion of time spent in each of the states in each interval. ${ }^{9}$ A correspondence analysis on the matrix thus formed, with individuals in the rows and time spent in each state during each interval in the columns, provides a means to summarize the information by selecting the factors with the highest inertia (Deville, 1982). Then using an ascending hierarchical classification is possible to determine typologies of trajectories. The typologies thus constructed takes account not only of the sequence of states, but also the periods spent in the different states. It also keeps all individuals in the analysis, reducing data heterogeneity with minimum information loss.

As Robette and Thibault (2008) remark harmonic analysis performs better when attention is focused on the duration of certain stages and to distinguish small and specific groups. By contrast, optimal matching is a better choice for analysing trajectories by type of transition and when mobility is the focus of attention, given that is more sensitive to transitions, notably at the start of the trajectory when changes are more frequent. In our case, OMA is also considered to be more appropriate as allow us to take into account the point in time at which transformation is carried out by using time-dependent substitution costs.

\footnotetext{
${ }^{9}$ As derived from explanation, QHA relies on two choices: the number of intervals in which the study period must be divided and the amplitude of intervals, because these amplitudes do not necessarily have to be of equal length.
} 
The Optimal Matching Analysis (OMA) was first introduced to the Social Sciences by Abbott and Forrest (1986) and was originally created for alignment of sequences in the Biological Sciences. ${ }^{10}$ As it was mentioned above, the idea behind OMA is that the similarity between sequences can be expressed as the cost of transforming one sequence into another by applying a set of operations. There are three types of operations: substitution (a state is substituted by another one), insertion (a state is inserted into the sequence) and deletion (a state is deleted altogether). ${ }^{11}$ The latter two operations are subsumed to so-called indel operations. ${ }^{12}$ As noted in the literature, substitutions emphasize the ordering of events whereas indel operations stress the occurrence of events. Each type of operation is assigned a cost. The OMA looks for the less "expensive" combination of operations required to transform one sequence into another and assume this cost is the distance that separates both sequences (the similarity distance). Then, a pair of sequences with a small distance means that they are similar, while pairs with a large distance are more distinct. Such comparison is repeated for all sequence pairs in the sample to obtain a distance matrix that measures how much every sequence resembles each other. This distance matrix is used in the cluster analysis to identify representative pathways by grouping together sequences that are similar to each other, i.e. that have the smallest distance between themselves.

Therefore, the first step in sequence analysis is to assign costs to each operation. Nevertheless, we focus in another question before beginning to explain how to assign costs to each operation: the length of trajectories. As it was

\footnotetext{
${ }^{10}$ For a review, see Abbott and Tsay (2000).

${ }^{11}$ Substitution is also interpreted as a combination of an insertion and a deletion. For example, transforming $\mathrm{ABA}$ into AAA involves deleting $\mathrm{B}$ and then inserting an $\mathrm{A}$.

${ }^{12}$ These two operations used to be treated in the same way, given that deleting an element from a sequence is the same as inserting this element in the other sequence. For example, the difference between sequences $\mathrm{ABA}$ and $\mathrm{AA}$ can be eliminated either by removing $\mathrm{B}$ from $\mathrm{ABA}$ or adding $\mathrm{B}$ to AA.
} 
explained in the data section, survey allows us to collect information about the labour states occupied between two dates: the date of completion vocational education and the date of survey. But the month of completion vocational education and the month of interview are not always the same for all individuals. Consequently, the length of sequences is not the same. However, the measure used here, the dynamic Hamming dissimilarity (Lesnard, 2006), can only handle sequences of equal length. For this reason, youth labour trajectories have been truncated and only contain the states occupied since vocational training is finished for a further three years. In this way, sequence length is 36 months.

Coming to the issue of assignment costs, it must be said that this step is critical because different costs have influence on the resulting distance matrix. Ideally, setting values to operations costs should be based on theoretical grounds but there is not always a theory supporting this. Given that in our context, there are no accepted measures of quantitative differences between states to guide us in the assignment of the costs (Malo and Muñoz-Bullón, 2003), we have followed the criteria established by the dynamic Hamming dissimilarity measure (Lesnard, 2006), where the substitution costs, derived from the data itself, are time dependent, and the indel costs have no sense. ${ }^{13}$ This strategy has also been applied to study the employment mobility (Malo and Muñoz-Bullón, 2003) and the string to adulthood (Aassve et al., 2007).

Hence, the cost of substituting a state (for example, unemployment) by another one (employment) is assumed that it is related to the transition frequencies between those states. More specifically, substitution costs are inversely proportional to frequencies, that is, the less frequent is a transition between two

${ }^{13}$ Assign costs to indel operations is useless when the sequences have equal length. 
states, the bigger is the cost to substitute one of the states by the other one. Besides, we accept that substitution costs also vary with time. That means that probability of staying in a state, for instance employment, two years later after completing vocational training is not the same as to get a job just right away after ending. In this sense, the transition matrix which contains the transition frequencies between the six states is not fixed, but time dependent. Summarizing, the substitution costs have been calculated using the monthly transition frequencies derived from data taking into account the following expression,

$$
\operatorname{cost}(a, b)=\left\{\begin{array}{cc}
4-p\left(X_{t}=a / X_{t-1}=b\right)+p\left(X_{t}=b / X_{t-1}=a\right)+ & \\
p\left(X_{t+1}=a / X_{t}=b\right)+p\left(X_{t+1}=b / X_{t}=a\right) & a \neq b \\
0 & a=b
\end{array}\right.
$$

where $p$ stands for the transition frequencies between state $a$ (or $b$ ) to state $b$ (or $a$ ) in a given month. Each matrix of substitution costs is symmetric and its size is equal to the number of states.

The dynamic algorithm evaluates all possible solutions (combinations of operations to transform a sequence into the other) and returns the "cheapest" one. ${ }^{14}$ As a result, a symmetric matrix with size equal to the number of sequences that contains the similarity between each pair of sequences is obtained. The matrix is called a distance matrix as each cell $\left(a_{i j}\right)$ contains the distance between the individual sequence $i$ and individual sequence $j$. The cells on the diagonal of the matrix contain only zeros because they represent the distance between a sequence and itself.

\footnotetext{
${ }^{14}$ We use a Stata program created by Lesnard (2006). The program generates several files that contains the series of monthly transition matrices, substitution cost matrices and the distance matrix.
} 
Next, we apply a cluster analysis on this distance matrix to group sequences into an undetermined number of clusters which indentify representative pathways. A difficulty to apply the cluster analysis is the great number of repeated sequences that appear in our data. ${ }^{15}$ As Martin et al. (2008) noticed cluster analysis is affected by ties. For this reason, the cluster analysis is only applied to unique sequences, that is, we eliminate the sequences repeated.

Cluster analysis is a well-known technique that requires making some decisions about the different clustering algorithms and the identification of the appropriate number of clusters. In relation to the cluster algorithm, there exists a large amount of methods of grouping and there is not a clear criterion to decide between them. We have chosen an agglomerative hierarchical method, the Ward method, because it finds most homogeneous clusters and it is the most popular between similar studies (Scherer, 2001; Brzinsky-Fay, 2007; Martin et al., 2008). Besides, it seems to provide the most reasonable results when we compare the performance of different cluster algorithms.

Like other hierarchical agglomerative methods, at the start of the process, each cell in the distance matrix - each pair of sequences $i j$ - represents a cluster and has a distance $a_{i j}$ associated to it. These primitive clusters are then progressively merged and, at every round, the distance between each two clusters is recalculated using the criterion applied by the Ward linkage.

The Ward's clustering criterion is based on the error sum-of-squares, ESS, which is defined as the sum of the squared distances of individuals from the centre of gravity of the cluster to which they have been assigned. Initially, ESS is 0,

\footnotetext{
${ }^{15}$ A previous description of sequences based on aggregated measures related to the number of states, the time spent on states and most frequent sequences has discovered that a high percentage of young people share the same trajectory.
} 
since every individual is in a cluster of its own. At each stage the link created is the one that makes the smallest increase in the ESS.

In mathematical terms, the error sum-of-squares of a group $r$ is given by

$$
\operatorname{ESS}_{r}=\sum_{m=1}^{n_{r}} \sum_{j=1}^{p}\left(X_{r j m}-\bar{X}_{r j}\right)^{2}
$$

where $X_{r j m}$ denotes the value of variable $X_{j}$ in the $m$ element of group $r$ (in our case the variables will be the distance between trajectories included in cluster $r$ ).

In each step the algorithm merges those groups $r$ and $s$ that minimize

$$
E S S_{t}-\left(E S S_{r}+E S S_{s}\right)=\frac{n_{r} n_{s}}{n_{r}+n_{s}} d_{r s}^{2}
$$

with $t$ is the combine cluster resulting from the fusion cluster $r$ and $s$ and $d_{r s}^{2}$ the squared Euclidean distance between the center of gravity of clusters $r$ y $s$.

The final question to be solved is the identification of the appropriate number of clusters. We have considered the change in the agglomeration coefficient represented in the dendrogram to take this decision. ${ }^{16}$ Nevertheless, after comparing some different results, the final solution (seven clusters) has also taken into account contextual arguments, an internal analysis of homogeneity and the characteristics of clusters that help to understand what youth in each cluster have in common and whether each cluster has analytically meaningful. ${ }^{17}$

\section{B. Typologies of trajectories}

We begin by describing the clusters and the characteristics of those youths belonging to each one. ${ }^{18}$ The mean number of months spent in each state by

\footnotetext{
${ }^{16}$ Other authors propose to display and visualize results using self-organizing maps (Giret and Rousset, 2007).

${ }^{17}$ To evaluate the robustness of the cluster analysis, we have investigated the presence of more or fewer clusters, but the identification described in the paper with seven clusters was the clearest.

${ }^{18}$ To describe clusters we retrieve the sequences repeated.
} 
members of each cluster and the mean number of episodes in each state are included in Table 3. Bold fields indicate the dominant states within each cluster. Some other background characteristics such as gender and professional family are also considered to describe clusters (Table 4). Finally, some figures, representing the monthly states distribution for each cluster, allow us to differentiate clusters not only for their composition but for the location and order of states and give us a more detailed picture of the transition process, making yet easier to recognize which is the dominant state in each cluster (see Figure 1). A combination of all these measures helps us to evaluate if the trajectories could be considered linear transitions or non-linear transitions, having defined a non-linear transition as the one that involves breaks, changes of direction or unusual sequences of events (Furlong et al., 2006).

[Table 3 about here]

The largest group by far is the "continuously working in a full-time job". More than one third of the young people (70\%) have followed a trajectory basically composed by the "full-time employment" state. Within this cluster, the mean number of months in employment is 33 , clearly superior to the number of months for the total sample. Also, this cluster is characterised by the diversity of sequences as it contains the highest number of different sequences (1350). Thus, occasional and short spells in other states can be found dispersed across the trajectory. Continuous full-time work participation is slightly more common among males than females.

Cluster 2 ("part-time job") is also characterized by sequences essentially formed by employment, but in contrast to the first cluster, young people spent most of the first three years after finishing vocational education working in part- 
time jobs. Over the whole period (36 months), the mean duration in part-time employment for members of this group was 24 months. Considering both the time spent in part-time and full-time jobs, the total duration is similar to the previous cluster. The participation in the labour market tends to be full-time at the end of the trajectory as it could be appreciated in Figure 1. Approximately 3.5\% of young people belong to this cluster and it is clearly a female cluster (59\%).

Sequences belonging to cluster 3 ("non-formal education") are basically composed of inactivity periods (studying in not formal education) and employment periods (3.4\% of individuals belongs to this cluster). In general, people from this cluster distribute their time spending 18 months studying and just over one year working in full-time jobs. A closer look at Figure 1 shows another important explanation of how the trajectories are formed; inactivity periods usually are part of the early years of the trajectory and employment periods are more likely to appear at the end of the trajectory. This cluster hardly display gender imbalance.

A typical sequence from cluster 4 ("full-inactivity") corresponds to an individual spending just about two thirds of time not studying and not working (total inactivity). This cluster could be the most problematic given that the mean duration in employment is the smallest one (6 months) and inactivity is a common issue along the trajectory. Fortunately, not many young people belong to this cluster (approximately $2 \%$ of the sample, mostly females).

There are two clusters (5 and 7) where the "inactivity but studying in formal education" state is the dominant, but we can appreciate some important differences between them. Young people in cluster 5 ("return to formal education") spend at least half of the time studying (in cluster 7 time spent in this 
state is longer, 23 months) but what really differentiate them is that they return to education after a period away. Besides, this cluster seems to be the more heterogeneous taking into account the time spent in other states. The break or change in the direction of the transition to work that we appreciate in this cluster, it makes possible to describe the transition period as not linear, according to the above definition. The cluster 7 ("continue formal education") is the second largest group (13\%) and corresponds to young people that decide to improve their education before entering into the labour market. Nevertheless, the size of these two clusters is lower than that from cluster 1, which means that vocational lowersecondary education is more likely to lead to employment and less likely to lead to higher education.

From a political and social point of view, sequences in cluster 6 ("unemployment") could be considered those having the worst behaviour. There is a clear dominance of unemployment, with an average of 24 months distributed in two spells of unemployment. Long spells of unemployment are usually found at the beginning of the trajectory. This type of trajectory is only shared by the $5 \%$ of the total sample and it is clearly a female trajectory.

One of the main questions address by this study is whether qualifications and skills of graduates have different effects in outcomes in the case of individuals with vocational education. For this reason, we examined in detail the distribution of the different occupational families by cluster (see Table 4). First of all, it should be noted that there are some occupational families more numerous. Students in vocational education tend to choose: Administration and management (18.5\%), Health (12.5\%), Electricity and electronics (11.3\%) and Transport and maintenance of motor vehicles $(8.6 \%)$. The trajectory described in cluster 1 
continues being the most frequent even when we distinguish by professional families. Nevertheless, the percentage of young people with this kind of trajectory varies considerably, from $85.5 \%$ for Mechanical manufacturing to $55.8 \%$ to Chemistry (or $32.1 \%$ in the case of Arts and craftwork). As it can be observed, the occupational families occupying the first positions are not the same that present a higher number of students. Also cluster 7 ("continue formal education") is the second trajectory more frequent for all families. In particular, those families for which paths are more related to education, postponing the entry to labour market, are Arts and Craftwork, Agriculture activities, Chemistry, Image and sound and Hotel industry and Tourism.

For some occupational families the partial-time job is more frequent than unemployment. For example, the trajectory of part-time employment is more common for the Chemistry, Image and sound and Construction and civil work families. Surprisingly, a pathway basically composed of unemployment is not found for those students who studied the Construction and civil work family. An explanation to this result maybe the favourable economic situation for this sector in the analised period.

[Table 4 about here]

\section{Multivariate analysis: determinants of belonging to clusters}

In order to provide a more comprehensive treatment of differences between clusters we have estimated a multinomial logit model. The model allows us to isolate the effect of some demographic and educational factors on the probability of each individual to belong to a particular cluster. In this respect, we evaluate the role of these variables in determining individual trajectories. The dependent 
variable for the model takes values 1 to 7 and reflects the cluster to which individual is assigned. As explanatory factors we have included gender, age, the geographical area where the individual finished his studies and several dummies collecting the area of specialization in vocational education (occupational families). It has been necessary to join some occupational families in order to get enough size for each cluster. ${ }^{19}$ As mentioned above, young men and women do not have the same preferences when deciding to study vocational education and our data show clearly this gender segregation by specialization. Thus the colinearity between these two factors makes difficult to obtain accurate estimates when both of them are jointly included. For this reason, we have estimated two alternative specifications (each one with one of the two variables) to evaluate the impact of gender and occupational family in the probability of belonging to a cluster.

Before commenting the results, we have to note that the independence of irrelevant alternatives assumption, that is whether each of the dependent variable categories can be considered statistically independent of the others, has not been rejected (see Table 6).

Estimation results of both specifications appear in Table 5 and are presented as relative risk ratios which, in the case of a quantitative variable, give the proportionate change in the relative risk of belonging to a given pathway rather than the full-employment trajectory when the variable changes by one unit. In the case, of a qualitative variable it gives the proportionate change in the relative risk for the collective of young people define by the variable compare with the reference category. For example, the relative risk ratio of 1.98 for the female

${ }^{19}$ Information about the families that are aggregated could be found in Table 2. 
variable in the part-time pathway outcome indicates that females have a relative risk of belonging to the part-time pathway rather than full-time pathway $98 \%$ higher than males.

Regarding gender the results show that females have a higher relative risk ratio of belonging to part-time, full inactivity, unemployment and continue formal education clusters rather than full-employment than men.

Turning to age, both specifications show that as age increases the relative probability of belonging to clusters more related with education (cluster 3,5 y 7 ) against full-employment reduces.

\section{[Table 5 and 6 about here]}

There are also significant differences when considering the area of residence as a proxy of the situation of local labour markets. The common results to both specifications, indicates that the success in transitions after finishing vocational education is greater if young is living in Madrid, because those young have a lower risk ratio to follow any trajectory distinct to the full-time trajectory (the reference area is the south of Spain which is characterized by the largest unemployment rate). Results also suggest that living in eastern and north-eastern regions also reduces the risk ratio of belonging to unemployment cluster, that is, there is advantaged in terms of the availability of jobs in these local labour market.

The area of specialization chosen has also significant explanatory power for the type of pathway followed. If the occupational family is Agriculture, Services1, Services2, Chemistry or Health the relative risk ratio to belong to cluster 7 (continue formal education) is higher. On the contrary, Industry and Construction specialization reduces this risk ratio and also the risk ratio to belong to any cluster 
distinct to the full-time employment. Health, Chemistry, Services1 and Services2 are also specializations where a part-time pathway has greater probability than full-time pathway, and having studied Electricity and electronics and Transport reduce the risk ratio of belonging to unemployment cluster.

Behind these results is the productive model prevailing in Spain in those years of economic expansion, based on the construction sector, its ancillary industries and on domestic demand. As a result there was a growing supply of semi-skilled jobs in those sectors that could be covered by these youth. Hence, the success of the occupational families related to construction, industry, electronics and electricity and transport.

On the other hand, the activities most closely related to the services sector and health have also had a development and generated jobs, but in these sectors there has been much more competition among the youth with vocational training and university studies that eventually has led to the need of more education, in some cases, combine with part-time jobs. ${ }^{20}$

\section{Robustness analysis}

As already mentioned in the methodology, results depend greatly on the strategy used to measure distances between sequences and the criteria to group sequences. For this reason, we have considered two alternative specifications of the substitution costs matrix to assess the robustness of the results. The first one consists of setting to one the costs of substituting each pair of states, a usual starting point substitution costs (Lesnard, 2010). As a second alternative, costs

\footnotetext{
${ }^{20}$ At this respect, there exists a vast empirical literature that shows that Spain has suffered a problem of over-education, mainly in the services sector, involving many young people with a university degree in jobs which require less qualifications (Dolado et al., 2000; Budria and MoroEgido, 2008).
} 
have been theoretically grounded reflecting our own assumptions about the inherent distinctions between the states. Given that the school-to-work-transition process connects the educational system and the labour system, transitions between states belonging to the educational system (or labour system) are supposed to be easier and it is assigned lower costs than transitions from one system to the other one. The transitions from/to full inactivity (nor studying nor working) have been considered the most difficult one and it has the greatest costs (see matrix in Figure 2). For each alternative, we have running a cluster analysis to make groups of trajectories, taking as input the distance matrix obtained from the optimal matching analysis with the corresponding substitution costs matrix. In order to make easier the comparison with the previous results, the number of clusters is the same as in the case of dependent substitution costs.

The degree of similarity of both alternatives in relation to the previous one can be illustrated by a correspondence matrix which cross-tabulates the population distributions obtained with two different partitions (Robette and Thilbaut, 2008). It shows whether the individuals of a cluster from the first partition are concentrated in a single cluster of the second partition or scattered between several different ones. In Table 7, the seven-cluster distribution with timedependent substitution costs spans the rows and the seven-cluster distribution with unit costs spans the columns, whereas at the bottom of this table, the seven-cluster distribution with fixed costs spans the columns. In both cases, it is showed only slight differences with the reference time-dependent costs chosen in previous section, above all in the case of fixed costs.21 Most sequences are grouped in the same clusters, what supposes that more than $70 \%$ of them are identical classified.

\footnotetext{
${ }^{21}$ The robustness of the results with respect to different costs matrices was expected. Most of papers about the school-to-work-transition commented previously have also experimented with different variants of substitution costs and arrived at the same results.
} 
Where we found more diversion is in those clusters related to inactivity as a consequence of studying in the formal education system. A detailed revision of the time-dependent substitution costs matrix confirms us that there are some similarities to the fixed theoretic matrix proposed here.

Also, a correspondence rate summarizing the degree of similarity between the two partitions can be calculated by means of the index proposed in Robette and Thibault (2008), which sum up the mode of each line and each column, dividing it by the double of the total sample size, that is

$$
\sigma=\frac{\sum_{i} \max _{j} n_{i j}+\sum_{j} \max _{i} n_{i j}}{2 N}
$$

where $n_{\mathrm{ij}}$ represents the number of trajectories belonging simultaneously to the $\mathrm{i}$ th cluster of the first partition and the jth cluster of the second partition, and where $N$ is the total population.

The correspondence between the distributions obtained with time-dependent costs and unit costs is $87 \%$ and between time-dependent cost and fixed costs $90 \%$. The two alternative costs give similar results, a good indicator of their robustness.

\section{Conclusions}

It has been widely documented that youth transitions have become increasingly long and complex what implies that few individuals follow identical routes to enter into the labour market and most faced routes involving movements in both directions (in and out of employment). However, the analysis of the school-towork transition for Spanish young people with vocational lower-secondary education shows that pathways are not substantial distinct across individuals and most trajectories may be classified as linear, with a successful integration into the 
labour market. This result is in agreement with educational systems including a substantial training component in a real working context, in which the school-towork transition seems to be direct and smooth.

Specifically, the cluster analysis based on dissimilarity measures has suggested seven coherent typologies of transitions from school to work. Differences between them are basically due to the dominant labour state and to the order and location of the states. The largest cluster by far is composed of sequences characterized by a direct entry into the labour market with very short spells in the other states. It is remarkable to note that this cluster is also the most frequent when we distinguish by occupational families. This finding supports the idea that the areas covered by the actual occupational families respond to the current demand of labour market, at least, in this period in which the boom experienced by the Spanish economy has made possible the integration of most young people. The second cluster involves extended participation in education. Again, this result seems to confirm an adequate behaviour of vocational students. They try to improve their skills in order to get a better position into the labour market. Those clusters more problematic, where young people experience unfavourable long unemployment spells or spend most time without studying nor working, are less numerous. In spite of its small size, it would be useful to take a closer look at the characteristics of young people in the "full inactivity" cluster to understand better their transition to work. But this requires further research.

On the other hand, differences between men and women have been found. Women are more likely to experience trajectories with a greater participation in part-time jobs or inactivity. In general, women sequences show greater variation and its integration is less direct. 
As a final thought, the paper highlights one point often overlooked when transition to school-to-work is concentrated in a comparative analysis between countries or in a national aggregated analysis. Spain is included in most European studies as a country where young people experience serious difficulties to enter into the labour market. Besides, some Spanish studies supported this statement. However, this paper shows the opposite in the case of students with vocational education.

The favorable situation of the Spanish economy has contributed greatly to the rapid entry to the labour market. In this sense, it would be interesting to know how the trajectories would be in the case of an adverse economic situation. Besides, several aspects of the school-to-work transition (such as the quality of jobs attained by these young people with vocational lower-secondary education) have not been taken into account in this paper and they should help to improve our analysis in the future.

\section{References}

Aassve, A., Billari, F. C. and Piccarreta, R. (2007) Strings of adulthood: a sequence analysis of young British women's work-family trajectories, European Journal of Population, 23, 369-388.

Abbott, A. and Forrest, J. (1986) Optimal matching methods for historical sequences, Journal of Interdisciplinary History, 16, 471-494.

Abbott, A. and Tsay, A. (2000) Sequence analysis and optimal matching methods in sociology: review and prospect, Sociological Methods and Research, 29, 333. 
Armstrong, D. and McVicar, D. (2000) Value added in further education and vocational training in Northern Ireland, Applied Economics, 32, 1727-1736.

Arum, R. and Shavit, Y. (1995) Secondary vocational education and the transition from school to work, Sociology of Education, 68, 187-204.

Bonnal, L., Mendes, S. and Sofer, C. (2002) School-to-work transition: apprenticeship versus vocational school in France, International Journal of Manpower, 23, 426-442.

Brzinsky-Fay, C. (2007) Lost in transition? Labour market entry sequences of school leavers in Europe, European Sociological Review, 23, 409-422.

Brzinsky-Fay, C., Kohler, U. and Luniak, M. (2006) Sequence analysis with Stata, The Stata Journal, 6, 435-460.

Budria, S. and Moro-Egido, A. I. (2008) Education, educational mismatch and wage inequality: evidence for Spain, Economics of Education Review, 27, 332341.

Cachon, L. (2000) "National Report Spain", in Documentation of European Conference "Transition from initial vocational training into stable employment”, INBAS, Frankfurt am Main, 89-106.

Casquero, A. (2007) Transición del sistema educativo al mercado laboral en España. Especial referencia a la formación profesional, Analistas Económicos de Andalucía, Málaga (España).

Chan, T. W. (1995) Optimal matching analysis: a methodological note on studying career mobility, Work and Occupation, 22, 467-490.

Corrales, H. and Rodríguez, B. (2004) Transition from education to first significant job in Spain: the influence of educational attainment, in 
Proceedings of the 58th International Atlantic Economic Conference, Chicago, Illinois.

Davia, M. A. (2004) La inserción laboral de los jóvenes en la Unión Europea, Consejo Económico y Social, Madrid.

Deville, J. C. (1974) Méthodes statistiques et numériques de l'analyse harmonique, Annales de l'INSEE, 15, 3-101.

Deville, J. C. (1982) Analyses de données chronologiques qualitatives: comment analyser des calendriers ? Annales de l'INSEE, 45, 45-104.

Dolado, J. J., Felgueroso, F. and Jimeno, J. F. (2000) Youth labour markets in Spain: education, training and crowding-out, European Economic Review, 44, 943-958.

Dolton, P. J., Makepeace, G. H. and Trebble, J. G. (1994) The youth training scheme and the school-to-work transition, Oxford Economic Papers, 46, 629657.

Espinasse, J. M. (1993) Enquêtes de cheminement, chronogrammes et classification automatique, Notes $d u$ Lirhe, 159, 93-19, CEREQ.

Everitt, B. S., Landau, S. and Leese, M. (2001) Cluster analysis, Oxford University Press.

Furlong, A., Cartmel, F. and Biggart, A. (2006) Choice biographies and transitional linearity: re-conceptualising modern youth transitions, Papers, 79, 225-239.

Gangl, M. (2003) The structure of labour market entry in Europe: a typological analysis, in Muller, W. and Gangl, M. (eds.) Transition from education to work in Europe, Oxford University Press. 
Giret, J. and Rousset, P. (2007) Classifying qualitative time series with SOM: the typology of career paths in France, in Proceedings of the 9th International Work-Conference on Artificial Neural Networks, Springer, Berlin, pp. 757-764.

Halpin, B. (2010) Optimal matching analysis and life-course data: the importance of duration, Sociological Methods and Research, 38, 365-388.

Halpin, B. and Chan, T. W. (1998) Class careers as sequences: an optimal matching analysis of work-life histories, European Sociological Review, 14, 111-130.

Homs, O. (2009): Vocational training in Spain. Toward the knowledge of society, Social Studies Collection No. 25, Fundación La Caixa, Barcelona.

Iannelli, C. and Raffe, D. (2007) Vocational upper-secondary education and the transition from school, European Sociological Review, 23, 49-63.

Instituto Nacional de Estadística (INE) (2007) Encuesta de transición educativo formativa e inserción laboral. Resumen Metodológico. Available at www.ine.es/daco/daco42/etefil/notaetefil.pdf (acessed 17 December 2009).

Lesnard, L. (2006) Optimal matching and the social sciences, Working Paper No. 1/2006, CREST-INSEE, France.

Lesnard, L. (2010) Setting cost in optimal matching to uncover contemporaneous socio-temporal patterns, Sociological Methods and Research, 38, 389-419.

Malo, M. and Muñoz-Bullón, F. (2003) Employment status mobility from a lifecycle perspective: a sequence analysis of work histories in the BHPS, Demographic Research, 9, 119-162.

Martin, P., Schoon, I. and Ross, A. (2008) Beyond transitions: applying Optimal Matching analysis to life course research, International Journal of Social Research Methodology, 11, 179-199. 
McVicar, D. and Anyadike-Danes, M. (2002) Predicting successful and unsuccessful transitions from school to work by using sequence methods, Journal of the Royal Statistical Society (Series A), 165, 317-334.

Merino, R. (2006) Two or three vocational training pathways? An assessment and the current situation in Spain, European Journal of Vocational Training, 37, $52-67$.

OECD (2000) From initial education to working life. Making transitions work, Paris: OECD.

Quintini, G. and Manfredi, T. (2009) Going separate ways? School-to-work transitions in the United States and Europe, OECD Social, Working Paper in Employment and Migration No. 90, OECD, France.

Raffe, D. (2003) Pathways linking education and work: a review of concepts, research, and policy debates, Journal of Youth Studies, 6, 3-19.

Robette, N. and Thibault, N. (2008) Comparing qualitative harmonic analysis and optimal matching: an exploratory study of occupational trajectories, Population-E, 63, 533-556.

Ryan, P. (2001) The school-to-work transition: a cross-national perspective, Journal of Economic Literature, 39, 34-92.

Ryan, P. (2003) Evaluating vocationalism, European Journal of Education, 38, 147-162.

Scherer, S. (2001) Early career patterns: a comparison of Great Britain and West Germany, European Sociological Review, 17, 119-144.

Scherer, S. (2005) Patterns of labour market entry - long wait or career instability? An empirical comparison of Italy, Great Britain and West Germany, European Sociological Review, 21, 427-440. 
1

2

3

4

5

6

7

8

9

10

11

12

13

14

15

16

17

18

19

20

21

22

23

24

25

26

27

28

29

30

31

32

33

34

35

36

37

38

39

40

41

42

43

44

45

46

47

48

49

50

51

52

53

54

55

56

57

58

59

60

Schoon, I., McCulloch, A., Joshi, H. E., Wiggins, D. and Bynner, J. (2001) Transitions from school to work in a changing social context, Young, 9, 4-22.

Shavit, Y. and Muller, W. (2000) Vocational secondary education: where diversion and where safety net? European Societies, 2, 29-50. 
Table 1. Classification of labour states

\begin{tabular}{cl}
\hline Code & Description \\
\hline INEFSE & Inactivity but studying non-formal education \\
INESE & Inactivity but studying in the educational system \\
INNE & Inactivity and not studying \\
U & Unemployment \\
PT & Part-time employment (less than 20 hours per week) \\
FT & Full-time employment (equal or greater than 20 hours per week) \\
\hline
\end{tabular}

Table 2. Occupational families

\begin{tabular}{lll}
\hline Code & Description & Aggregation grouping \\
\hline ADM & Administration and Management & Administration and Management \\
AGR & Agriculture activities & Agriculture \\
ART & Arts and Craftwork & Services2 \\
CHE & Chemistry & Chemistry \\
CON & Construction and Civil Work & Industry and Construction \\
ELE & Electricity and Electronics & Electricity and Electronics \\
FOI & Food Industry & Industry and Construction \\
GRA & Graphic Arts & Services2 \\
HEA & Health & Health \\
HOT & Hotel Industry and Tourism & Services1 \\
IMA & Image and Sound & Services2 \\
INS & Installation and Maintance & Industry and Construction \\
MAR & Maritime Industry and Fisheries & Agriculture \\
MEC & Mechanical Manufacturing & Industry and Construction \\
PER & Personal Image & Services2 \\
SPO & Phisical and Sporting Activities & Services2 \\
SOC & Sociocultural and Community & Services1 \\
& Services & \\
TEX & Textiles, Leather and Fur & Industry and Construction \\
TRM & Trade and Marketing & Services1 \\
TRA & Transport and Maintance of Motor & Transport and Maintance of Motor \\
& Vehicles & Vehicles \\
WFC & Wood, Furniture and Cork & Industry and Construction \\
\hline
\end{tabular}


Table 3. Description of clusters by the mean number spent in each state and the mean number of spells

\begin{tabular}{|c|c|c|c|c|c|c|c|c|c|c|c|c|c|c|c|}
\hline \multirow[b]{2}{*}{ Cluster } & \multirow[b]{2}{*}{ Title } & \multirow[b]{2}{*}{$\mathrm{N}$} & \multirow{2}{*}{$\begin{array}{c}\% \\
\text { female }\end{array}$} & \multicolumn{2}{|c|}{ INEFSE } & \multicolumn{2}{|c|}{ INESE } & \multicolumn{2}{|c|}{ INNE } & \multicolumn{2}{|c|}{$\mathbf{U}$} & \multicolumn{2}{|c|}{ PT } & \multicolumn{2}{|c|}{ FT } \\
\hline & & & & Dur. & Spell & Dur. & Spell & Dur. & Spell & Dur. & Spell & Dur. & Spell & Dur. & Spell \\
\hline 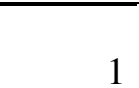 & $\begin{array}{l}\text { Continuously in full- } \\
\text { time job }\end{array}$ & 5373 & 42.8 & 0.22 & 0.04 & 0.18 & 0.03 & 0.45 & 0.10 & 1.91 & 0.54 & 0.23 & 0.04 & 33.01 & 1.37 \\
\hline & & & & $(1.40)$ & $(0.22)$ & $(1.21)$ & $(0.23)$ & $(1.97)$ & $(0.37)$ & $(3.61)$ & $(0.93)$ & $(1.45)$ & $(0.22)$ & $(4.69)$ & $(0.80)$ \\
\hline 2 & Part-time job & 264 & 58.7 & $\begin{array}{l}0.57 \\
(2.15)\end{array}$ & $\begin{array}{c}0.10 \\
(0.33)\end{array}$ & $\begin{array}{l}1.25 \\
(3.32)\end{array}$ & $\begin{array}{c}0.28 \\
(0.68)\end{array}$ & $\begin{array}{r}0.49 \\
(1.77)\end{array}$ & $\begin{array}{c}0.13 \\
(0.42)\end{array}$ & $\begin{array}{l}1.45 \\
(3.50)\end{array}$ & $\begin{array}{c}0.38 \\
(0.77)\end{array}$ & $\begin{array}{c}\mathbf{2 3 . 6 6} \\
(8.71)\end{array}$ & $\begin{array}{l}1.34 \\
(0.80)\end{array}$ & $\begin{array}{c}8.57 \\
(7.83)\end{array}$ & $\begin{array}{l}1.17 \\
(1.02)\end{array}$ \\
\hline 3 & Non-formal education & 261 & 46.7 & $\begin{array}{c}18.41 \\
(9.33)\end{array}$ & $\begin{array}{l}1.28 \\
(0.59)\end{array}$ & $\begin{array}{c}0.89 \\
(3.06)\end{array}$ & $\begin{array}{l}0.11 \\
(0.33)\end{array}$ & $\begin{array}{l}0.51 \\
(1.70)\end{array}$ & $\begin{array}{c}0.16 \\
(0.51)\end{array}$ & $\begin{array}{c}\mathbf{3 . 7 2} \\
(5.72)\end{array}$ & $\begin{array}{l}0.77 \\
(1.04)\end{array}$ & $\begin{array}{l}0.38 \\
(1.62)\end{array}$ & $\begin{array}{l}0.08 \\
(0.27)\end{array}$ & $\underset{(9.11)}{\mathbf{1 2 . 0 9}}$ & $\begin{array}{l}1.38 \\
(1.03)\end{array}$ \\
\hline 4 & Full inactivity & 132 & 57.6 & $\begin{array}{l}1.02 \\
(2.97)\end{array}$ & $\begin{array}{l}0.17 \\
(0.43)\end{array}$ & $\begin{array}{l}2.27 \\
(4.56)\end{array}$ & $\begin{array}{c}0.23 \\
(0.48)\end{array}$ & $\begin{array}{c}\mathbf{2 4 . 2 0} \\
(7.93)\end{array}$ & $\begin{array}{l}1.47 \\
(0.89)\end{array}$ & $\begin{array}{l}1.76 \\
(3.91)\end{array}$ & $\begin{array}{c}0.36 \\
(0.68)\end{array}$ & $\begin{array}{c}0.82 \\
(3.13)\end{array}$ & $\begin{array}{c}0.12 \\
(0.41)\end{array}$ & $\begin{array}{l}5.93 \\
(5.72)\end{array}$ & $\begin{array}{l}1.16 \\
(1.22)\end{array}$ \\
\hline 5 & $\begin{array}{l}\text { Return to formal } \\
\text { education }\end{array}$ & 206 & 45.1 & 5.45 & 0.50 & 18.35 & 1.27 & 1.95 & 0.25 & 3.39 & 0.4 & 0.72 & 0.14 & 6.14 & 1.10 \\
\hline 6 & Unemployment & 383 & 66.8 & $\begin{array}{l}(7.38) \\
0.48 \\
(1.57)\end{array}$ & $\begin{array}{l}(0.65) \\
0.12 \\
(0.39)\end{array}$ & $\begin{array}{l}(5.42) \\
0.19 \\
(1.25)\end{array}$ & $\begin{array}{l}(0.59) \\
0.03 \\
(0.20)\end{array}$ & $\begin{array}{l}(4.56) \\
0.37 \\
(1.82)\end{array}$ & $\begin{array}{l}(0.49) \\
0.07 \\
(0.29)\end{array}$ & $\begin{array}{c}(6.37) \\
\mathbf{2 4 . 0 1} \\
(7.47)\end{array}$ & $\begin{array}{l}(0.87) \\
2.09 \\
(1.26)\end{array}$ & $\begin{array}{l}(2.45) \\
0.63 \\
(2.46)\end{array}$ & $\begin{array}{l}(0.46) \\
0.12 \\
(0.41)\end{array}$ & $\begin{array}{c}(6.53) \\
\mathbf{1 0 . 3 3} \\
(7.16)\end{array}$ & $\begin{array}{l}(1.18) \\
1.82 \\
(1.44)\end{array}$ \\
\hline 7 & $\begin{array}{l}\text { Continue formal } \\
\text { education }\end{array}$ & 993 & 47.0 & $\begin{array}{l}0.37 \\
(1.71)\end{array}$ & 0.06 & 23.09 & 1.30 & 0.24 & 0.06 & 1.60 & 0.30 & 0.69 & 0.12 & 10.00 & 1.11 \\
\hline & & 7612 & 45.6 & 1.05 & & 3.76 & & 0.87 & & 3.06 & (1.00) & 1.15 & $(0.45)$ & 26.11 & \\
\hline
\end{tabular}

Source: ETEFIL-2005, own calculations.

Notes: INEFSE: Inactivity but studying non-formal education, INESE: Inactivity but studying in the educational system, INNE: Inactivity and not studying, U: Unemployment, PT: Part-time employment, FT: Full-time employment.

Standard deviations are given in parentheses. 
Table 4. Distribution of young people belonging to an occupational family by clusters (\%)

\begin{tabular}{|c|c|c|c|c|c|c|c|c|}
\hline $\begin{array}{l}\text { Occupational } \\
\text { family }\end{array}$ & $\begin{array}{c}\text { Continuously } \\
\text { in full-time } \\
\text { job } \\
\end{array}$ & Part-time job & $\begin{array}{l}\text { Non-formal } \\
\text { education }\end{array}$ & $\begin{array}{c}\text { Full } \\
\text { inactivity }\end{array}$ & $\begin{array}{l}\text { Return to formal } \\
\text { education }\end{array}$ & Unemployment & $\begin{array}{l}\text { Continue formal } \\
\text { education }\end{array}$ & Total \\
\hline ADM & 70.3 & 3.0 & 3.8 & 2.5 & 3.3 & 6.8 & 10.4 & 100 \\
\hline ART & 32.1 & 3.3 & 5.7 & 1.6 & 2.9 & 6.1 & 48.4 & 100 \\
\hline $\mathrm{CHE}$ & 55.8 & 8.5 & 3.1 & 1.8 & 3.1 & 7.6 & 20.1 & 100 \\
\hline $\mathrm{CON}$ & 73.9 & 6.5 & 2.2 & 0.0 & 2.2 & 0.0 & 15.2 & 100 \\
\hline GRA & 66.8 & 4.9 & 7.6 & 0.9 & 2.7 & 4.0 & 13.0 & 100 \\
\hline HEA & 67.1 & 4.5 & 3.3 & 2.1 & 2.7 & 7.3 & 13.0 & 100 \\
\hline HOT & 68.2 & 4.1 & 3.5 & 1.5 & 2.0 & 2.9 & 17.8 & 100 \\
\hline IMA & 55.3 & 7.1 & 7.6 & 1.5 & 4.6 & 5.6 & 18.3 & 100 \\
\hline INS & 80.6 & 1.3 & 1.9 & 0.6 & 3.4 & 2.2 & 10.0 & 100 \\
\hline SPO & 57.0 & 6.1 & 3.6 & 2.4 & 4.9 & 7.3 & 18.8 & 100 \\
\hline TEX & 62.3 & 4.4 & 1.5 & 1.5 & 2.9 & 13.0 & 14.5 & 100 \\
\hline TRA & 83.2 & 2.3 & 2.0 & 0.8 & 1.2 & 1.8 & 8.7 & 100 \\
\hline TRM & 63.1 & 5.0 & 4.3 & 2.8 & 2.2 & 8.2 & 14.5 & 100 \\
\hline \multirow[t]{2}{*}{ WFC } & 82.6 & 2.4 & 1.9 & 0.9 & 1.9 & 5.7 & 4.7 & 100 \\
\hline & 70.6 & 3.5 & 3.4 & 1.7 & 2.7 & 5.0 & 13.1 & 100 \\
\hline
\end{tabular}

Source: ETEFIL-2005, own calculations.

Note: See Table 2 for occupational families. 
Figure 1. Chronograms of the seven-cluster solution (number of individuals in each state)
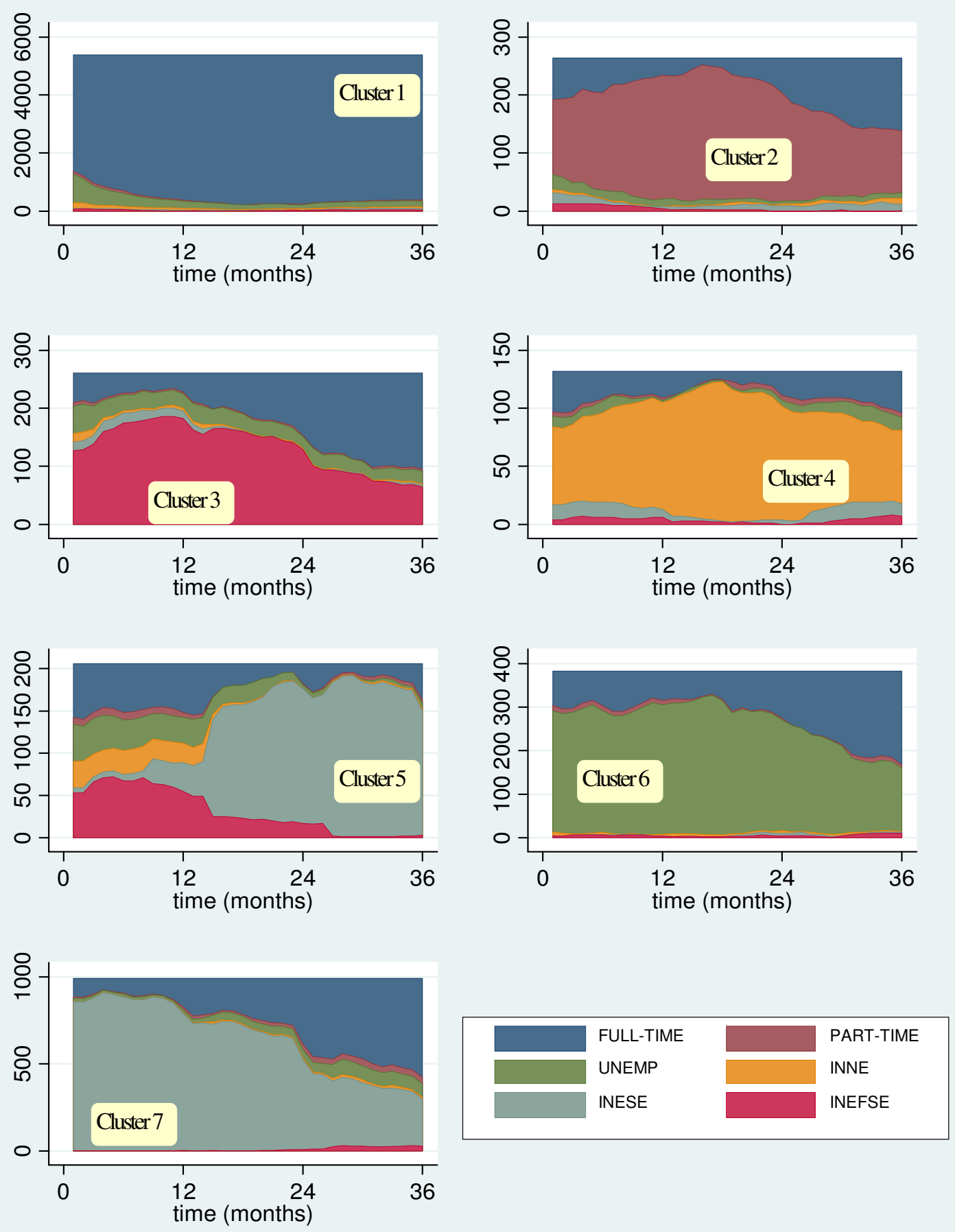

Source: ETEFIL-2005, own calculations.

Note: INEFSE: Inactivity but studying non-formal education, INESE: Inactivity but studying in the educational system, INNE: Inactivity and not studying. 
Table 5. Logit multinomial for the seven-cluster solution (relative risk ratios)

\begin{tabular}{|c|c|c|c|c|c|c|c|c|c|c|c|c|}
\hline & \multicolumn{6}{|c|}{ Model 1} & \multicolumn{6}{|c|}{ Model 2} \\
\hline & $\begin{array}{c}\text { Cluster } \\
2 \\
\end{array}$ & $\begin{array}{c}\text { Cluster } \\
3 \\
\end{array}$ & $\begin{array}{c}\text { Cluster } \\
4 \\
\end{array}$ & $\begin{array}{c}\text { Cluster } \\
5 \\
\end{array}$ & $\begin{array}{c}\text { Cluster } \\
6 \\
\end{array}$ & $\begin{array}{c}\text { Cluster } \\
7\end{array}$ & $\begin{array}{c}\text { Cluster } \\
2 \\
\end{array}$ & $\begin{array}{c}\text { Cluster } \\
3\end{array}$ & $\begin{array}{c}\text { Cluster } \\
4\end{array}$ & $\begin{array}{c}\text { Cluster } \\
5\end{array}$ & $\begin{array}{c}\text { Cluster } \\
6 \\
\end{array}$ & $\begin{array}{c}\text { Cluster } \\
7 \\
\end{array}$ \\
\hline Female & $1.98 * * *$ & 1.21 & $1.84 * * *$ & 1.15 & $2.76 * * *$ & $1.23 * *$ & & & & & & \\
\hline Age & 1.03 & $0.91 *$ & 0.89 & $0.83 * * *$ & 1.01 & $0.94 *$ & 1.00 & $0.89 *$ & $0.88 *$ & $0.82 * * *$ & 1.00 & $0.92 * * *$ \\
\hline East & 1.19 & 0.75 & 1.06 & $2.07 * *$ & $0.46 * * *$ & 1.00 & 1.28 & 0.79 & 1.09 & $2.11 * *$ & $0.47 * * *$ & 1.07 \\
\hline Center & $0.55^{*}$ & 0.83 & 1.28 & 1.15 & 0.92 & 0.81 & 0.63 & 0.94 & 1.39 & 1.23 & 1.01 & 0.90 \\
\hline Northeast & 1.02 & 0.83 & 0.64 & 1.51 & $0.36 * * *$ & $0.62 * * *$ & 1.17 & 0.98 & 0.71 & 1.68 & $0.38 * * *$ & $0.72 *$ \\
\hline Northwest & 0.56 & 1.04 & 1.82 & 1.02 & 1.32 & $0.61 * *$ & 0.66 & 1.22 & $2.05^{*}$ & 1.14 & $1.46^{*}$ & $0.71 *$ \\
\hline Madrid & $0.44 * * *$ & $0.56^{* *}$ & 0.64 & $0.47 * *$ & $0.34 * * *$ & $0.35 * * *$ & $0.53 * *$ & $0.60 * *$ & 0.68 & $0.48 * *$ & $0.36 * * *$ & $0.40 * * *$ \\
\hline Agriculture & & & & & & & 1.53 & 0.68 & 0.70 & 0.90 & $0.33 *$ & $2.03 * * *$ \\
\hline $\begin{array}{l}\text { Industry and } \\
\text { Construction }\end{array}$ & & & & & & & $0.55^{*}$ & $0.42 * * *$ & $0.35^{* *}$ & $0.57 *$ & $0.43 * * *$ & $0.66 * *$ \\
\hline Services1 & & & & & & & $1.61 *$ & 1.1 & 0.98 & 0.71 & 0.90 & $1.70 * * *$ \\
\hline Services2 & & & & & & & $1.87 * *$ & $1.62 *$ & 0.87 & 1.05 & 0.88 & $2.27 * * *$ \\
\hline $\begin{array}{l}\text { Transport } \\
\text { Electricity } \\
\text { and }\end{array}$ & & & & & & & 0.67 & $0.43 * *$ & $0.26 * *$ & $0.34 * *$ & $0.22 * * *$ & 0.73 \\
\hline Electronics & & & & & & & $0.32 * *$ & 0.78 & $0.44^{*}$ & 1.07 & $0.30 * * *$ & 0.83 \\
\hline Chemistry & & & & & & & $3.12 * * *$ & 1.01 & 0.91 & 1.18 & 1.16 & $2.18 * * *$ \\
\hline Health & & & & & & & $1.64 *$ & 0.93 & 0.96 & 1.02 & 1.15 & $1.43 * *$ \\
\hline $\begin{array}{l}\text { Log L } \\
\text { Pseudo R2 }\end{array}$ & $\begin{array}{c}-7837.7 \\
0.03\end{array}$ & & & & & & $\begin{array}{c}-7719.1 \\
0.05\end{array}$ & & & & & \\
\hline $\begin{array}{l}\text { Notes: Refer } \\
\text { Southern re }\end{array}$ & ice path & is $f$ & & & & & & with & & n studi & $\begin{array}{l}\text { and liv } \\
\text { and } 10\end{array}$ & $\begin{array}{l}\text { ir } \\
\text { le }\end{array}$ \\
\hline
\end{tabular}


Table 6. Small-Hsiao tests of IIA assumption

\begin{tabular}{lcccccc} 
& \multicolumn{3}{c}{ Model 1 } & Model 2 \\
\hline Omitted & chi2 & P>chi2 & evidence & chi2 & P>chi2 & evidence \\
\hline Part-time job & 28.990 & 0.901 & for Ho & 56.657 & 0.944 & for Ho \\
Non-formal education & 26.136 & 0.955 & for Ho & 63.622 & 0.823 & for Ho \\
Full Inactivity & 28.824 & 0.905 & for Ho & 65.808 & 0.767 & for Ho \\
Return to formal education & 30.016 & 0.875 & for Ho & 57.969 & 0.927 & for Ho \\
Unemployment & 29.215 & 0.896 & for Ho & 62.903 & 0.839 & for Ho \\
Continue formal education & 26.371 & 0.952 & for Ho & 63.276 & 0.831 & for Ho \\
Full time job & 31.375 & 0.833 & for Ho & 62.173 & 0.855 & for Ho \\
\hline
\end{tabular}

Ho: Odds(Outcome-J vs Outcome-K) are independent of other alternatives.

Figure 2. Fixed substitution costs

\begin{tabular}{c|cccccc|} 
& $\mathrm{U}$ & $\mathrm{FT}$ & INEFSE & INNE & PT & INESE \\
$\mathrm{U}$ & 0 & & & & & \\
FT & 1,2 & 0 & & & & \\
INEFSE & 1,2 & 1,3 & 0 & & & \\
INNE & 1,4 & 1,4 & 1,4 & 0 & & \\
PT & 1,2 & 1,1 & 1,3 & 1,4 & 0 & \\
INESE & 1,2 & 1,3 & 1,1 & 1,4 & 1,3 & 0
\end{tabular}

Note: See Table 1 for codes of states.

Table 7. Comparison of clusters with different substitution costs matrix

\begin{tabular}{|c|c|c|c|c|c|c|c|c|c|}
\hline & \multicolumn{7}{|c|}{ Unit costs } & \multirow[b]{2}{*}{ Total } \\
\hline & & 1 & 2 & 3 & 4 & 5 & 6 & 7 & \\
\hline \multirow{8}{*}{ 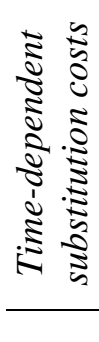 } & Full-time job & 4970 & 9 & 362 & 2 & 1 & 18 & 11 & 5373 \\
\hline & Part-time job & 7 & 249 & 0 & 1 & 0 & 1 & 6 & 264 \\
\hline & Non-formal education & 129 & 0 & 21 & 91 & 1 & 16 & 3 & 261 \\
\hline & Full inactivity & 9 & 4 & 2 & 112 & 2 & 3 & 0 & 132 \\
\hline & Return to formal education & 0 & 0 & 5 & 26 & 153 & 22 & 0 & 206 \\
\hline & Unemployment & 26 & 0 & 48 & 0 & 0 & 308 & 1 & 383 \\
\hline & Continue formal education & 55 & 19 & 0 & 1 & 377 & 5 & 536 & 993 \\
\hline & Total & 5196 & 281 & 438 & 233 & 534 & 373 & 557 & 7612 \\
\hline
\end{tabular}

\begin{tabular}{|c|c|c|c|c|c|c|c|c|c|}
\hline & \multicolumn{7}{|c|}{ Fixed costs } & \multirow[b]{2}{*}{ Total } \\
\hline & & 1 & 2 & 3 & 4 & 5 & 6 & 7 & \\
\hline \multirow{8}{*}{ 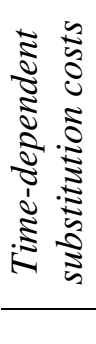 } & Full-time & 5292 & 8 & 4 & 0 & 1 & 57 & 11 & 5373 \\
\hline & Part-time & 4 & 258 & 0 & 0 & 1 & 1 & 0 & 264 \\
\hline & Non-formal education & 42 & 0 & 185 & 0 & 0 & 31 & 3 & 261 \\
\hline & Full inactivity & 27 & 0 & 0 & 89 & 13 & 3 & 0 & 132 \\
\hline & Return to formal education & 17 & 0 & 29 & 0 & 138 & 22 & 0 & 206 \\
\hline & Unemployment & 85 & 0 & 0 & 1 & 0 & 297 & 0 & 383 \\
\hline & Continue formal education & 79 & 19 & 2 & 0 & 372 & 27 & 494 & 993 \\
\hline & Total & 5546 & 285 & 220 & 90 & 525 & 438 & 508 & 7612 \\
\hline
\end{tabular}

